\title{
A INCLUSÃO DE ALUNOS PÚBLICO ALVO DA EDUCAÇÃO ESPECIAL NO ENSINO FUNDAMENTAL I ATRAVÉS DO OLHAR DOS PROFESSORES
}

\author{
THE INCLUSION OF STUDENTS WHO ARE THE TARGET-AUDIENCE OF SPECIAL \\ EDUCATION IN PRIMARY SCHOOL I THROUGH THE EYES OF THE TEACHERS
}

\author{
Relma Urel Carbone CARNEIRO ${ }^{\mathrm{i}}$ \\ Flávia UEHARA ${ }^{\text {ii }}$
}

\begin{abstract}
RESUMO: Este estudo se propôs a analisar como tem se dado a inclusão escolar de alunos público-alvo da Educação Especial nas séries iniciais do Ensino Fundamental. Para tanto desenvolvemos uma pesquisa qualitativa utilizando como procedimento metodológico o Estudo de Caso. Foi aplicado um questionário a 13 professores de classe comum atuantes em uma escola municipal de uma cidade do interior do estado de São Paulo, que tinham em suas turmas alunos com deficiência. Os resultados demonstraram que a matrícula do aluno com deficiência na classe comum não significa que ele esteja incluído nesta turma, que a concepção dos professores sobre essa inclusão é na maioria das vezes negativa, os professores não se percebem como agentes das mudanças necessárias, reivindicam formação, apoio estrutural, pedagógico e humano. Concluímos que a inclusão escolar faz parte de um movimento que pressupõe mudança de modelo, de estrutura e de política, e se constrói a partir de dentro, com análise crítica do que está posto e reflexão propositiva de para onde vamos.
\end{abstract}

PALAVRAS-CHAVE: Inclusão escolar. Trabalho docente. Ensino fundamental I.

ABSTRACT: This study had the aim to analyze how school inclusion of students who are the target-audience of Special Education has been taking place in the initial grades of Primary School. For this purpose, we developed a qualitative research that used Case Study as the methodological procedure. We applied a questionnaire to 13 teachers of regular classes working at a municipal school from an inland town in São Paulo state who had in their classes some students with disabilities. Results demonstrated that the mere enrollment of a student with disability in the regular classroom does not mean they are included in the class and that the teachers' concept of such inclusion is, most of the times, negative; teachers do not experience themselves as the agents of the necessary changes, they demand training, besides structural, pedagogical and human support. Our conclusion is that school inclusion is part of a movement that assumes change of model, structure and politics and builds itself from inside out, with critical analysis of what is proposed and propositional reflexion on where we are going.

KEYWORDS: School inclusion. Teaching work. Primary school I.

\section{Introdução}

A educação como um direito de todos - embora presente enquanto princípio desde o século XVII com Comenius, por exemplo, em sua Didática Magna - e como 
preceito legal universal na Declaração Universal dos Direitos Humanos de 1948, como prática efetiva no sistema educacional brasileiro é relativamente nova. A Constituição Brasileira, pautada em princípios democráticos, apresenta em seu artigo 205 que:

A educação, direito de todos e dever do Estado e da família, será promovida e incentivada com a colaboração da sociedade, visando ao pleno desenvolvimento da pessoa, seu preparo para o exercício da cidadania e sua qualificação para o trabalho (BRASIL, 1988).

Em continuidade, no artigo 206 a Constituição estabelece que o ensino será ministrado com base em alguns princípios, sendo que alguns deles dizem respeito à igualdade de condições para o acesso e permanência na escola; liberdade de aprender, ensinar, pesquisar e divulgar o pensamento, a arte e o saber; garantia de padrão de qualidade, entre outros. A partir da Constituição, muitos documentos nacionais e internacionais reiteram a educação como um direito inalienável de todo cidadão. No entanto, historicamente temos a constatação de que vários grupos foram alijados do sistema educacional por razões variadas como: sociais, culturais, econômicas, religiosas, fisiológicas, entre outras. Dentre esses grupos encontra-se aquele das pessoas com deficiências, transtornos globais de desenvolvimento e altas habilidades/superdotação, hoje definidos como público-alvo da Educação Especial. Incluir esse grupo no "todos" da educação, implica em uma modificação do sistema de forma a considerar suas características e especificidades.

Segundo relatórios do Censo Escolar da Educação Básica do Instituto Nacional de Estudos e Pesquisas Educacionais Anísio Teixeira (INEP) (2014), o número de matriculas na Educação Básica de alunos público-alvo da Educação Especial em classes regulares de escolas comuns aumentou significativamente nos últimos anos, passando de 387.031 em 2009 para 698.768 em 2014. De acordo com os dados do Censo, 54,8\% das escolas brasileiras possui alunos com necessidades educacionais especiais matriculados em turmas regulares de ensino, ou seja, mais da metade das escolas do país já incluem alunos com deficiências. Tais indicadores nos levam a refletir sobre como vem ocorrendo o processo de inclusão de alunos público alvo da Educação Especial nas escolas regulares, visto que a inserção destes ocorreu, em grande parte, apenas nos últimos anos.

Alguns questionamentos advindos das reflexões desencadeadas em uma disciplina do Programa de Pós-graduação em Educação Escolar da FCLAr, chamada "Trabalho docente no contexto da educação inclusiva", em que foram discutidos alguns 
conceitos como os de trabalho docente, inclusão escolar, fracasso escolar, entre outros, nos fizeram formular algumas perguntas:

$\checkmark$ Incluir legalmente significa incluir de fato?

$\checkmark$ Como os professores têm percebido a inclusão de alunos público-alvo da Educação Especial em classes comuns?

$\checkmark$ Como tem se dado a prática pedagógica destes professores para com alunos da Educação Especial?

$\checkmark$ Que tipo de apoios esses professores estão recebendo?

A partir dessas questões nos propusemos a realizar um estudo sobre como a inclusão de alunos público-alvo da Educação Especial vem acontecendo em um município do interior do estado de São Paulo. Optamos por investigar este fenômeno nos anos iniciais do Ensino Fundamental pelas seguintes razões: mais da metade dos alunos público-alvo da educação especial matriculados em escolas das redes estaduais e municipais no país frequentam este nível de ensino; no município em questão aproximadamente 55\% das matriculas realizadas na Educação Especial são feitas para alunos do $1^{\circ}$ ao $5^{\circ}$ ano do Ensino Fundamental; embora todos os níveis de ensino da Educação Básica sejam importantes, cada um com suas características de especificidades, e a Educação Superior, embora não obrigatória, também exerça um papel imprescindível na formação do cidadão e do país, as séries iniciais do Ensino Fundamental correspondem a um período de extrema relevância, por se responsável pela garantia de acesso ao indivíduo à leitura, escrita e às operações matemáticas básicas, elementos necessários à garantia de seus direitos básicos como cidadão.

\section{Método}

Esta pesquisa seguiu uma abordagem qualitativa e utilizou como procedimento metodológico o Estudo de Caso, que segundo Yin possibilita investigar "um fenômeno contemporâneo dentro de seu contexto da vida real, especialmente quando os limites entre o fenômeno e o contexto não estão claramente definidos" (YIN, 2010, p. 32). Conforme Lüdke; André, 1986, p. 18-20, os estudos de caso visam a descoberta, dão ênfase à interpretação em contexto, buscam retratar a realidade de maneira aprofundada, permitem generalizações naturalísticas, e buscam representar os diferentes e às vezes conflitantes pontos de vista presentes numa situação social. Como instrumento de coleta de dados, elaboramos um questionário que foi aplicado a 13 professores de uma escola 
municipal de Ensino Fundamental que oferecia atendimento nas séries iniciais. A referida escola possuía 508 alunos no momento da coleta de dados, dos quais 17 eram diagnosticados como alunos público-alvo da Educação Especial que recebiam atendimento educacional especializado.

A análise dos dados se deu mediante a organização dos dados em quadros e gráficos que possibilitaram a leitura de todas as respostas a uma mesma pergunta de forma direta, permitindo, assim, uma análise aprofundada. Como dificuldade apontamos o fato de que alguns professores não responderam todas as questões.

\section{Resultados e discussões}

A partir da junção das respostas dadas a cada uma das questões e da leitura sistemática das mesmas foi possível analisar, ainda que de forma pontual, como tem se dado a inclusão de alunos público-alvo da Educação Especial, matriculados no ensino fundamental I (séries iniciais) em uma escola municipal de uma cidade de porte médio do interior do estado de São Paulo.

Quadro 1. Questão 1 do questionário aplicado aos professores.

\begin{tabular}{|l|c|}
\hline Questão 1 & Tempo de atuação como professor. \\
\hline Professor 1 & 10 meses \\
\hline Professor 2 & 6 anos \\
\hline Professor 3 & 10 anos \\
\hline Professor 4 & 11 anos \\
\hline Professor 5 & 12 anos \\
\hline Professor 6 & 12 anos \\
\hline Professor 7 & 13 anos \\
\hline Professor 8 & 13 anos \\
\hline Professor 9 & 18 anos \\
\hline Professor 10 & 19 anos \\
\hline Professor 11 & 20 anos \\
\hline Professor 12 & 23 anos \\
\hline Professor 13 & 30 anos \\
\hline
\end{tabular}

Fonte: Elaboração dos autores. 
O tempo de atuação como professor dos participantes da pesquisa variou de 6 meses a 30 anos, sendo que apenas um professor era iniciante na carreira. Todos os outros tinham experiência de mais de seis anos, sendo a maioria bastante experiente na profissão. Esse dado é bastante relevante, uma vez que a inclusão de alunos públicoalvo da Educação Especial é algo relativamente recente em nossas políticas educacionais e em nossa realidade escolar, portanto, esses professores provavelmente não tiveram formação para uma atuação inclusiva e nem vivenciaram isso durante toda a trajetória profissional.

Quadro 2. Questão 2 do questionário aplicado aos professores.

\begin{tabular}{|l|c|}
\hline Questão 2 & $\begin{array}{c}\text { Já atuou como professor em turmas que possuíam alunos público-alvo } \\
\text { da educação especial? Se sim, qual o tipo de deficiência ou transtorno } \\
\text { global do desenvolvimento do aluno? }\end{array}$ \\
\hline Professor 1 & Sim. Deficiência visual e deficiência intelectual. \\
\hline Professor 2 & Sim. Deficiência intelectual, cegueira e autismo. \\
\hline Professor 3 & Sim. Deficiência intelectual. \\
\hline Professor 4 & Sim. Atraso de desenvolvimento com comprometimento cognitivo. \\
\hline Professor 5 & Sim. Dificuldade de aprendizagem, sem diagnostico específico. \\
\hline Professor 6 & Sim. Intelectual, entre outras. \\
\hline Professor 7 & Sim. Deficiência auditiva e autismo. \\
\hline Professor 8 & Sim. Deficiência Intelectual. \\
\hline Professor 9 & Sim. Síndrome de Down e deficiência intelectual. \\
\hline Professor 10 & Sim. Deficiência intelectual. \\
\hline Professor 11 & Sim. Vários. \\
\hline Professor 12 & Sim. Visual, auditiva e intelectual. \\
\hline Professor 13 & Sim. Dificuldades de Aprendizagem. \\
\hline
\end{tabular}

Fonte: Elaboração dos autores.

Todos os professores responderam que já atuaram com alunos público-alvo da Educação Especial. Nove (9) deles trabalharam com alunos com deficiência intelectual, três (3) com alunos com deficiência visual, dois (2) com alunos com autismo, dois (2) com alunos com deficiência auditiva, dois (2) com alunos com dificuldades de aprendizagem, um (1) com aluno com Síndrome de Down, um (1) professor relatou várias e outro respondeu entre outras. Alguns professores trabalharam com alunos com deficiências diferentes. A deficiência intelectual é sempre a mais presente nos relatos dos professores, o que merece uma análise particular, uma vez que é uma deficiência nem sempre comprovada e muitas vezes fruto de uma construção social, por negligência 
ou preconceito. Um estudo desenvolvido por Palma (2016) demonstra que pais de alunos identificados como deficientes intelectuais atendidos pelo atendimento educacional especializado de escolas do campo, não consideravam seus filhos deficientes, informando que só na escola essa deficiência era notada. Este olhar das famílias em relação aos filhos é mais um indicador de que a escola, muitas vezes, produz a deficiência. Paschoalick (1981, apud Mercer 1973) já afirmava isto:

O que parece, no entanto, ser o ponto central de discussão entre os especialistas, é que o conceito de deficiência mental (sic) não é alguma coisa aprioristicamente elaborada. Ele emerge do processo de interação social; é algo socialmente construído. Nesse sentido o deficiente mental (sic) é deficiente mental porque assim foi rotulado pelo grupo social de que é membro. Nesse caso, um indivíduo rotulado num determinado sistema social não será necessariamente em outro. (PASCHOALICK, 1981; p. 16)

Quadro 3. Questão 3 do questionário aplicado aos professores.

\begin{tabular}{|l|c|}
\hline Questão 3 & $\begin{array}{c}\text { Atualmente atua com algum aluno público-alvo da educação especial? } \\
\text { Se sim, qual tipo de deficiência ou transtorno global do } \\
\text { desenvolvimento do aluno? }\end{array}$ \\
\hline Professor 1 & Sim. Deficiência Intelectual. \\
\hline Professor 2 & Sim. Deficiência intelectual, cegueira e autismo. \\
\hline Professor 3 & Sim. Deficiência Intelectual. \\
\hline Professor 4 & Sim. Atraso de desenvolvimento com comprometimento cognitivo. \\
\hline Professor 5 & Sim. Autismo. \\
\hline Professor 6 & Sim. Intelectual. \\
\hline Professor 7 & Sim. Autismo. \\
\hline Professor 8 & Não. \\
\hline Professor 9 & Sim. Deficiência intelectual. \\
\hline Professor 10 & Sim. Deficiência intelectual. \\
\hline Professor 11 & Sim. \\
\hline Professor 12 & Sim. Visual e auditiva. \\
\hline Professor 13 & Sim. Deficiência visual. \\
\hline
\end{tabular}

Fonte: Elaboração dos autores.

As respostas a esta questão praticamente não diferem da anterior, com exceção de um professor que disse não, inclusive porque era objetivo da pesquisa que o professor respondente estivesse, preferencialmente, atuando com alunos público-alvo da Educação Especial. 
As respostas à questão 4 estão apresentadas a forma de gráfico com o intuito de demonstrar visualmente a discrepância entre aqueles que acreditam na inclusão de alunos público-alvo da Educação Especial em classes comuns como uma forma de mudar a escola para que a mesma seja para todos e aqueles que não acreditam nessa possibilidade.

Gráfico 1. Dados da questão 4.

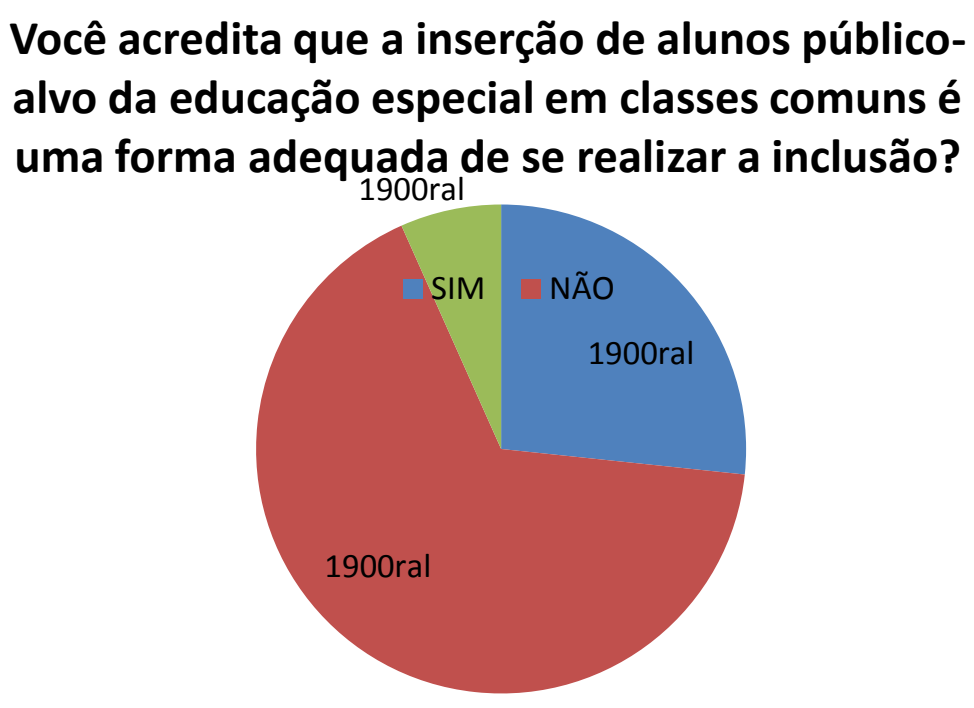

Fonte: Elaboração dos autores.

Quadro 4. Questão 4 do questionário aplicado aos professores.

\begin{tabular}{|l|c|}
\hline Questão 4 & $\begin{array}{c}\text { Você acredita que a inserção de alunos público-alvo da educação especial em } \\
\text { classes comuns é uma forma adequada de se realizar a inclusão? Por que? }\end{array}$ \\
\hline Professor 1 & $\begin{array}{r}\text { Sim. O aluno se desenvolve em suas capacidades, e convive com outras crianças. } \\
\text { Essa situação ocorrerá na vida em sociedade e em suas relações sociais. }\end{array}$ \\
\hline Professor 2 & $\begin{array}{r}\text { Sim e Não. Depende. Há alguns alunos que não têm condições de frequentar o } \\
\text { ensino regular. A família exige a matrícula, a escola atende a solicitação, oferece } \\
\text { o AEE também. Porém, tais casos são exemplos de uma "falsa" inclusão. " } \\
\text { inclusão não é para todos." }\end{array}$ \\
\hline Professor 3 & $\begin{array}{r}\text { Não. Porque são muitos alunos por professor e quando temos alunos deficiente } \\
\text { não temos tempo e nenhuma auxiliar para um apoio. }\end{array}$ \\
\hline Professor 4 & $\begin{array}{r}\text { Não. Porque o professor não tem formação adequada para isso, nas escolas não há } \\
\text { estrutura física e material para receber esses alunos e alguns alunos não deveriam } \\
\text { ser inclusos no ensino regular. }\end{array}$ \\
\hline Professor 5 & $\begin{array}{r}\text { Não. Da maneira como é estruturada atualmente a inclusão, falta materiais e } \\
\text { recursos materiais e humanos para atender estes alunos de forma adequada. }\end{array}$ \\
\hline Professor 6 & $\begin{array}{r}\text { Não. Não sou especialista e não há apoio em período integral (enquanto está na } \\
\text { sala; somente em horário contrário, que é pouco). }\end{array}$ \\
\hline Professor 7 & $\begin{array}{r}\text { Não. Porque não há ainda uma cultura de inclusão, recursos e estrutura adequada } \\
\text { para o efetivo trabalho, de modo que a inclusão ocorra. O incluir, o como incluir e }\end{array}$ \\
\hline
\end{tabular}




\begin{tabular}{|c|c|}
\hline & o para quê incluir são questões a serem compreendidas. \\
\hline Professor 8 & Sim e Não. Depende qual tipo de deficiência ou transtorno o aluno apresentar. \\
\hline Professor 9 & $\begin{array}{l}\text { Não. Porque não inclui o aluno com necessidades especiais, somente o coloca } \\
\text { dentro da sala de aula. }\end{array}$ \\
\hline Professor 10 & Depende do tipo de deficiência. \\
\hline Professor 11 & $\begin{array}{l}\text { Não. Porque essas crianças necessitam de acompanhamento constante para que } \\
\text { sua inclusão seja satisfatória. }\end{array}$ \\
\hline Professor 12 & Sim. Socialização. \\
\hline Professor 13 & $\begin{array}{c}\text { Não. Nós professores nem sempre estamos preparados para alguns casos, como } \\
\text { por exemplo, o meu aluno deficiente visual. }\end{array}$ \\
\hline
\end{tabular}

Fonte: Elaboração dos autores.

Apenas dois professores responderam sim, tendo como base de argumentação a socialização, e um deles considerou o desenvolvimento das capacidades desses alunos e a reprodução daquilo que é a vida em sociedade. Vale lembrar que a socialização é uma consequência natural do processo de escolarização, e não seu objetivo.

A fundamentação para o princípio inclusivo está embasada na garantia de igualdade de direitos e oportunidades e em um ensino de qualidade para todos como preceito democrático. Três professores ficaram no campo da incerteza, respondendo Sim e Não ou depende, e suas justificativas sugerem uma percepção equivocada do papel da escola, uma vez que o argumento para quem deve ou não ser incluído é o tipo de deficiência, ou seja, uma visão homogeneizadora da educação, em que o aluno é que tem que se adequar a uma estrutura pré-concebida, ficando a escola isenta de qualquer movimento no sentido de buscar respostas diferenciadas para atender as diversas necessidades dos alunos.

Os outros oito professores responderam que não, apontando como empecilhos o grande número de alunos nas classes, a falta de apoio auxiliar, falta de formação dos professores para essa tarefa, falta de recursos materiais, falta de estrutura física adequada, falta de recursos humanos e, por fim, falta de uma cultura de inclusão. Embora todos esses itens compreendam aspectos que precisam ser considerados e muitas vezes alterados na escola para transformá-la em inclusiva, a análise possível é que o entendimento de que essa estrutura só será alterada a partir da garantia de educação para todos e que cada um de nós somos responsáveis por ela, parece distante da compreensão dos professores.

O professor 7 falou que falta uma cultura de inclusão;; concordamos com ele, porém, ressaltamos que essa cultura deve emergir de uma prática pedagógica que 
garanta o direito de todos a educação, independente de conjunturas estruturais, associada a um movimento de mudança dessas conjunturas.

Gráfico 2. Dados da questão 5.

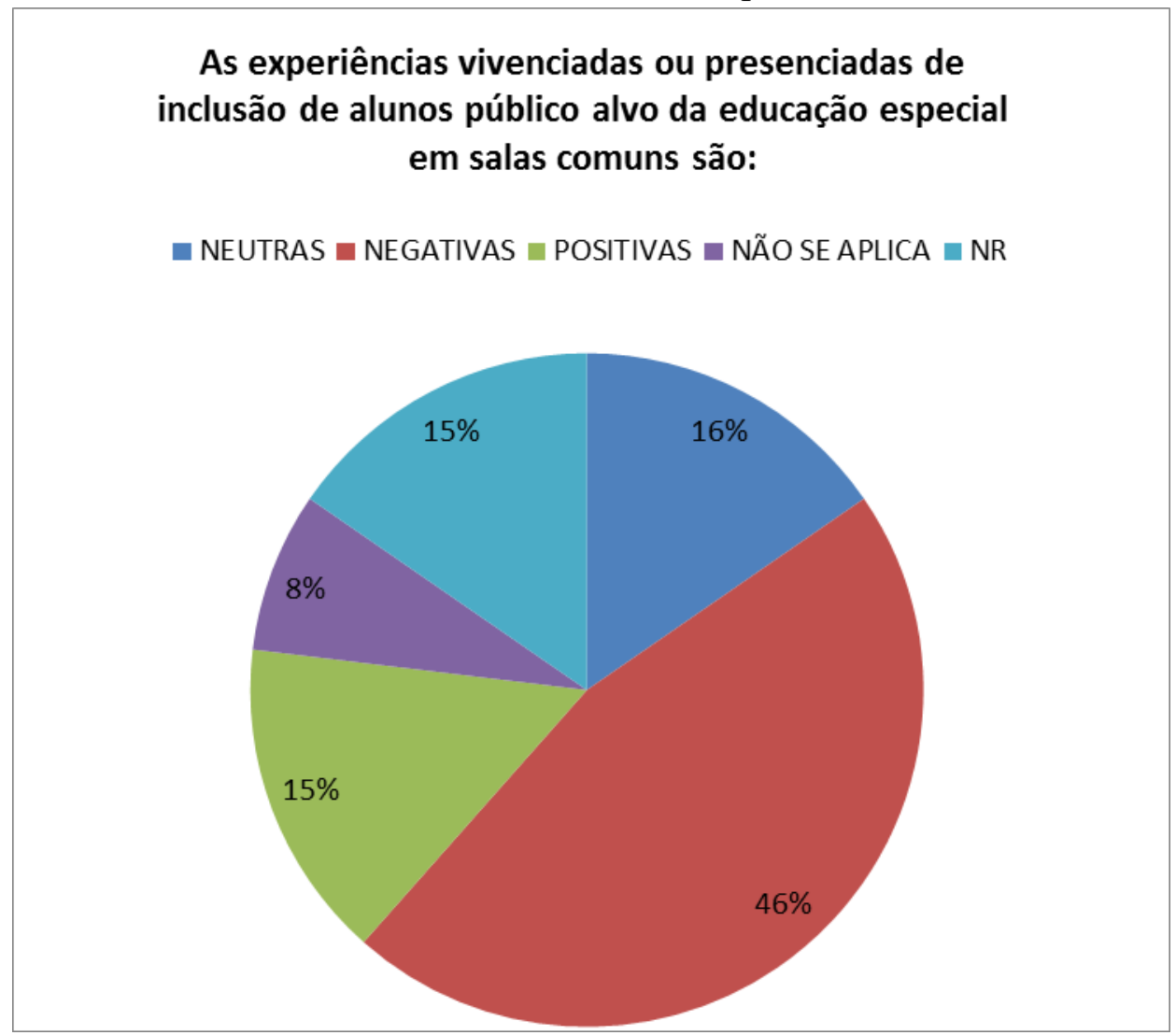

Fonte: Elaboração dos autores.

Quadro 5. Questão 5 do questionário aplicado aos professores.

\begin{tabular}{|l|l|}
\hline Questão 5 & $\begin{array}{l}\text { De maneira geral, as experiências vivenciadas ou presenciadas de inclusão de } \\
\text { alunos público-alvo da educação especial em salas comuns são ( ) positivas ( ) } \\
\text { negativas ( ) neutras ( ) não se aplica: }\end{array}$ \\
\hline Professor 1 & $\begin{array}{l}\text { Neutras. Em algumas situações o aluno está sendo prejudicado, pois não recebe uma } \\
\text { atenção específica, entretanto ele convive com outras crianças o que acaba sendo } \\
\text { bom em seu desenvolvimento social. }\end{array}$ \\
\hline Professor 2 & $\begin{array}{l}\text { Não se aplica. Depende. Há casos em que as experiências são positivas, outras vezes } \\
\text { negativas e ainda, há situações em que o aluno não se beneficia em nada do ensino } \\
\text { regular. }\end{array}$ \\
\hline Professor 3 & $\begin{array}{l}\text { Negativas. Pois, não se tem tempo suficiente para que possamos nos dedicar mais } \\
\text { tempo para o aluno. }\end{array}$ \\
\hline Professor 4 & $\begin{array}{l}\text { Negativas. Por falta de recurso e formação, não se consegue fazer com que o aluno } \\
\text { avance como deveria. }\end{array}$ \\
\hline Professor 5 & Neutras. \\
\hline
\end{tabular}




\begin{tabular}{|l|l|}
\hline Professor 6 & $\begin{array}{l}\text { Negativas. Em roda de conversa sobre um determinado assunto como por exemplo } \\
\text { "animais" fala de algum brinquedo, roupa ou comida que ganhou ou usou. }\end{array}$ \\
\hline Professor 7 & $\begin{array}{l}\text { Negativas. Frequentemente o aluno não é inserido no grupo com atividades } \\
\text { integradas; a quantidade de alunos dificulta o trabalho mais próximo com esse aluno. }\end{array}$ \\
\hline Professor 8 & $\begin{array}{l}\text { Depende, algumas crianças se socializam bem e aceitam realizar a atividade que foi } \\
\text { adaptada para ela. Outras crianças não realizam a atividade que foi adaptada para ela, } \\
\text { querem fazer igual ao das outras crianças. }\end{array}$ \\
\hline Professor 9 & $\begin{array}{l}\text { Negativas. Não tem direcionamento e tão pouco condições de trabalho com esses } \\
\text { alunos. }\end{array}$ \\
\hline Professor 10 & Depende do tipo e nível da deficiência. \\
\hline Professor 11 & $\begin{array}{l}\text { Negativas. Eles têm em alguns casos, interação social, mas são discriminados pelos } \\
\text { colegas. Interação cognitiva dificilmente ocorre. }\end{array}$ \\
\hline Professor 12 & Positivas. Socialização; Progresso cognitivo. \\
\hline Professor 13 & $\begin{array}{l}\text { Positivas. São positivas quando o quadro apresentado pelo aluno não é tão grave e se } \\
\text { torna positiva também para a socialização do aluno. }\end{array}$ \\
\hline
\end{tabular}

Fonte: Elaboração dos autores.

Dos 13 professores, a maior parte (46\%), assinalou que as experiências com alunos público-alvo da Educação Especial são negativas e apenas 15\% consideraram positivas, sendo que os demais optaram pelos campos Neutras, não se aplica ou não responderam a pergunta. As justificativas negativas abarcam parte dos problemas já apresentados anteriormente como quantidade de alunos, falta de recurso ou formação. É curioso como os professores têm dificuldades em refletir sobre o processo ensinoaprendizagem como um elemento capaz de fornecer formação e auxílio para a resolução de problemas. A prática inclusiva é a única possibilidade que temos de fazer as mudanças necessárias, sem ela não teremos os elementos base para encontrar o caminho. Infelizmente, os professores que responderam que as experiências são positivas se apoiam em argumentos externos, sem perceberem que as experiências que as convivências com as diferenças proporcionam são mútuas, que modificações nas estruturas e nas práticas pedagógicas beneficiam todos os envolvidos no processo. É preciso ampliar o conceito de aprendizagem, que obviamente abarca todo o conteúdo acadêmico- no entanto, não se resume a ele.

A questão 6 envolveu uma série de elementos considerados necessários na escola para favorecer a inclusão. O gráfico 3 mostra que em relação a infraestrutura adaptada, $72 \%$ dos professores responderam que sim e $28 \%$ responderam que não para esse quesito em sua escola. 
Gráfico 3. Dados da questão 6.

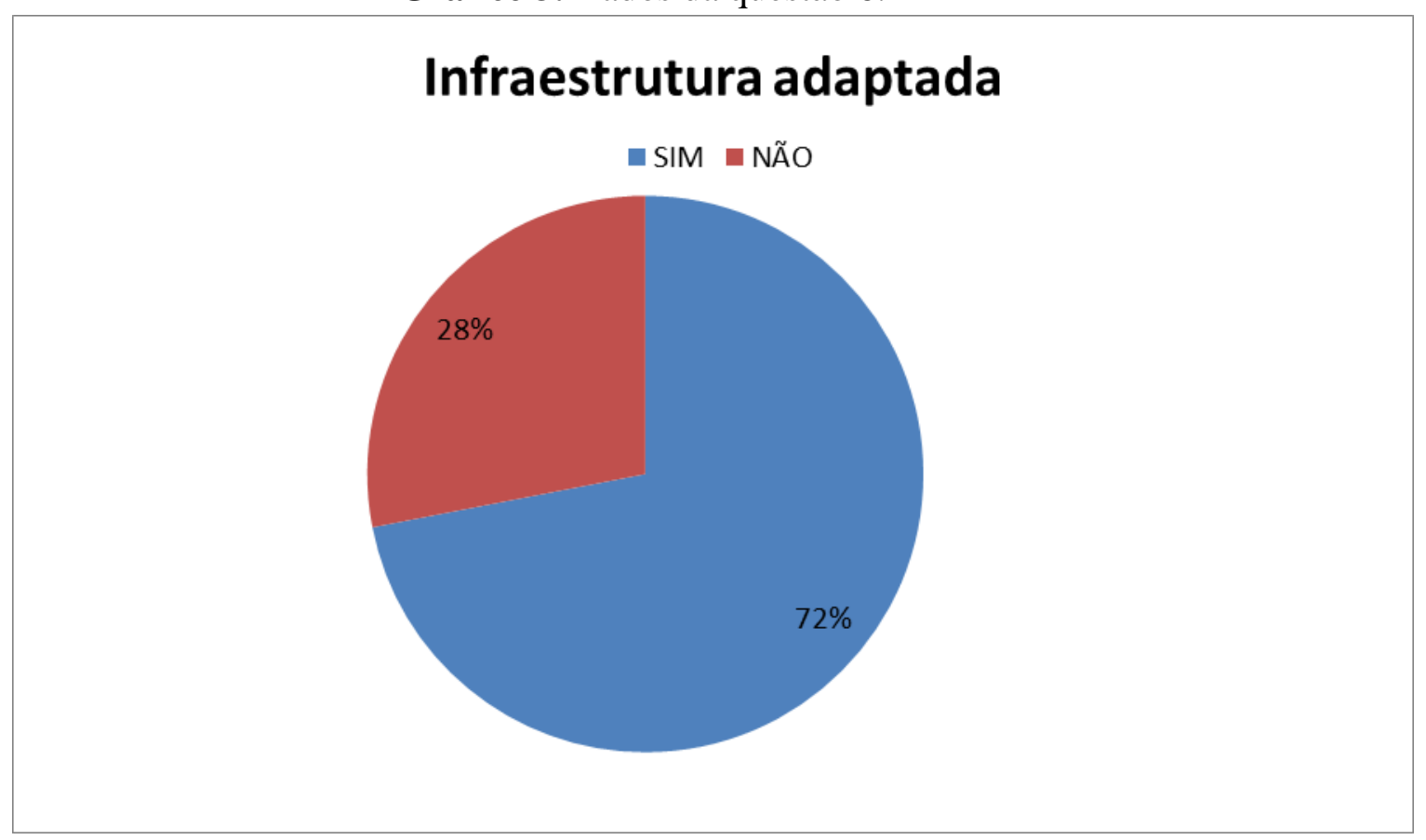

Fonte: Elaboração dos autores.

Quadro 6. Questão 6 do questionário aplicado aos professores.

\begin{tabular}{|l|l|}
\hline Questão 6 & $\begin{array}{l}\text { Na escola em que atua estão disponíveis para a inclusão de alunos público-alvo } \\
\text { da educação especial: infraestrutura adaptada? Ex. }\end{array}$ \\
\hline Professor 1 & Sim. Rampas e funcionários. \\
\hline Professor 2 & Sim. Rampas e banheiros. \\
\hline Professor 3 & Não. \\
\hline Professor 4 & Não. Banheiros adaptados e rampas. \\
\hline Professor 5 & Não. \\
\hline Professor 6 & Sim. Rampa. \\
\hline Professor 7 & Sim. Banheiros, sala de recursos e rampas. \\
\hline Professor 8 & Sim. Rampas e banheiros. \\
\hline Professor 9 & Não. \\
\hline Professor 10 & Sim. Sala de recursos. \\
\hline Professor 11 & Não. \\
\hline Professor 12 & Sim. \\
\hline Professor 13 & Sim. \\
\hline
\end{tabular}

Fonte: Elaboração dos autores. 
Os itens citados como exemplo desta infraestrutura se resumem a rampas, banheiros adaptados e sala de recursos, ou seja, infraestrutura física, demonstrando pouco conhecimento por parte dos professores sobre uma infraestrutura realmente adequada para uma escola atender alunos com todos os tipos de necessidades. Isso revela que caminhamos pouco no sentido da inclusão e por isso não conhecemos nem as necessidades e nem as soluções para elas.

Gráfico 4. Dados da questão 6.

\section{Materiais didáticos adaptados}

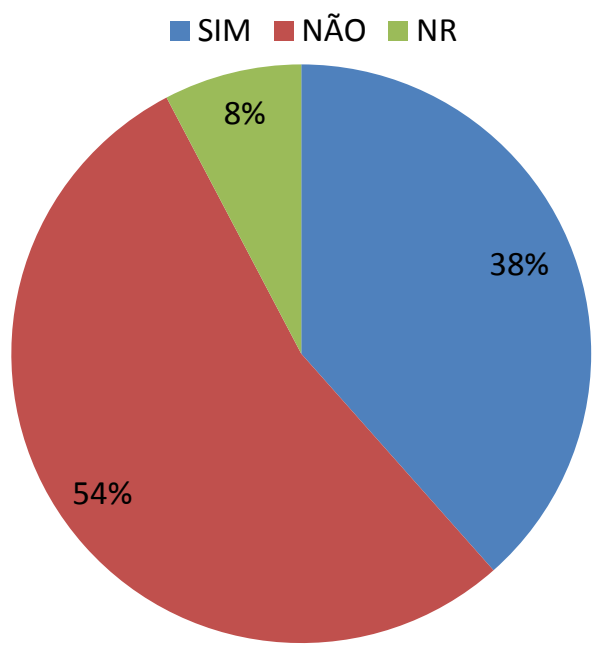

Fonte: Elaboração dos autores.

Quadro 7. Questão 6 do questionário aplicado aos professores.

\begin{tabular}{|l|l|}
\hline Questão 6 & $\begin{array}{l}\text { Na escola em que atua estão disponíveis para a inclusão de } \\
\text { alunos público alvo da educação especial: Materiais didáticos } \\
\text { adaptados ? Ex. }\end{array}$ \\
\hline Professor 1 & Não. \\
\hline Professor 2 & Sim. Na sala de recursos (apenas). \\
\hline Professor 3 & Não. \\
\hline Professor 4 & Não. Materiais em braile por exemplo. \\
\hline Professor 5 & Não. \\
\hline Professor 6 & Não. \\
\hline Professor 7 & Sim. Na sala de recursos: computadores, jogos. \\
\hline Professor 8 & Máquina Braille e impressora braile. \\
\hline Professor 9 & Não. \\
\hline Professor 10 & Sim. Computador e máquina Braile. \\
\hline
\end{tabular}




\begin{tabular}{|l|l|}
\hline Professor 11 & Não. \\
\hline Professor 12 & Sim. \\
\hline Professor 13 & Sim. \\
\hline
\end{tabular}

Fonte: Elaboração dos autores.

Em relação a existência de materiais didáticos adaptados em sua escola, 54\% disseram não estarem disponíveis, $38 \%$ disseram que existem na sala de recursos e citaram também materiais destinados ao aluno com deficiência visual, como máquina e impressora braile. Esse dado nos permite inferir que há um distanciamento entre o trabalho da sala de recursos e o da sala comum, sendo os materiais usados na sala de recursos exclusivo deste espaço, não sendo visto pelo professor da sala comum como um recurso da escola. Outro aspecto a ser analisado é que não aparece na resposta da maioria dos professores materiais didáticos destinados aos outros alunos com deficiência da escola, identificados pelos mesmos, em questão anterior, como sendo alunos com deficiência intelectual, auditiva, com autismo, entre outros, nem materiais pensados para alunos que, mesmo não tendo deficiência, poderiam se beneficiar de materiais pedagógicos diferenciados.

Gráfico 5. Dados da questão 6.

\section{Apoio da equipe pedagógica}

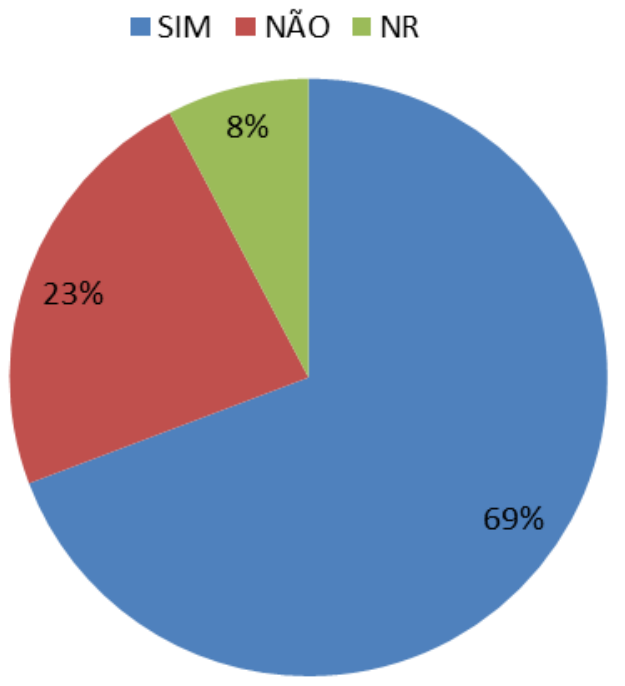

Fonte: Elaboração dos autores. 
Quadro 8. Questão 6 do questionário aplicado aos professores.

\begin{tabular}{|l|l|}
\hline Questão 6 & $\begin{array}{l}\text { Na escola em que atua estão disponíveis para a inclusão de alunos público-alvo } \\
\text { da educação especial: apoio da equipe pedagógica ? Ex. }\end{array}$ \\
\hline Professor 1 & Sim. Professora especialista. \\
\hline Professor 2 & $\begin{array}{l}\text { Ás vezes. Há professores que se recusam a trabalhar com alunos deficientes (os } \\
\text { aceitam em suas salas mas não desenvolvem atividades com os mesmos). }\end{array}$ \\
\hline Professor 3 & Não. \\
\hline Professor 4 & Sim. Professora da educação especial. \\
\hline Professor 5 & Sim. \\
\hline Professor 6 & Sim. Uma professora da Educação Especial que atende a todos. \\
\hline Professor 7 & $\begin{array}{l}\text { Sim. Professor do Atendimento Educacional Especializado (AEE) que atua na sala de } \\
\text { recursos; Professor Coordenador. }\end{array}$ \\
\hline Professor 8 & Sim. Professora AEE. \\
\hline Professor 9 & Não. \\
\hline Professor 10 & Sim. AEE. \\
\hline Professor 11 & Não. \\
\hline Professor 12 & Sim. \\
\hline Professor 13 & Sim. \\
\hline
\end{tabular}

Fonte: Elaboração dos autores.

O item sobre apoio da equipe pedagógica foi mencionado por $69 \%$ dos professores, mas com exceção de um professor que citou o professor coordenador, todos os outros se referem a professora do atendimento educacional especializado da sala de recursos como a única componente desta equipe de apoio pedagógico. Outro princípio inerente ao conceito de inclusão escolar é a necessidade de parceria e colaboração. Justamente porque não temos uma história de inclusão e não sabemos como fazê-la, o isolamento reforça a dificuldade. Friend (2002, p. 224), apresenta várias recomendações sobre ideias específicas e estratégias para promover práticas colaborativas nas escolas; a primeira e mais fundamental seria levar professores e administradores ao entendimento de que a colaboração é uma parte importante e crítica do funcionamento da escola. Ripley (1997), apontou que a colaboração envolve compromisso dos professores que irão trabalhar juntos, dos administradores da escola, do sistema escolar, e da 
comunidade. Envolve também tempo, suporte, recursos, pesquisas, monitoramento, e, acima de tudo, persistência.

Gráfico 6. Dados da questão 6.

\section{Apoio de profissionais especializados}

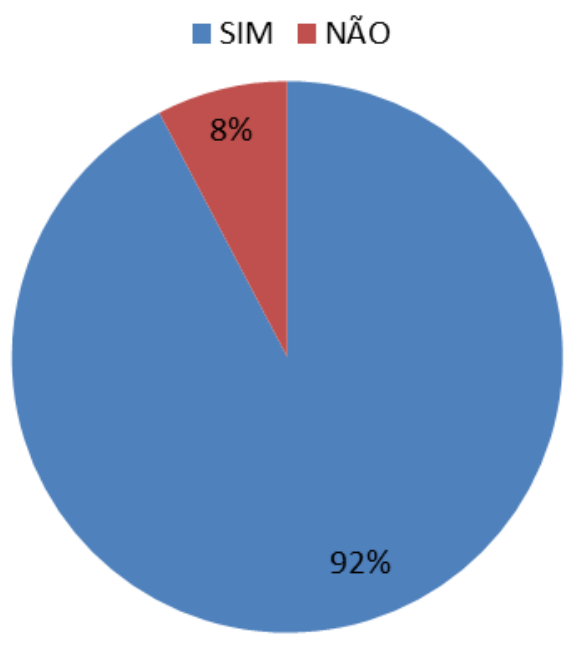

Fonte: Elaboração dos autores.

Quadro 9. Questão 6 do questionário aplicado aos professores.

\begin{tabular}{|l|l|}
\hline Questão 6 & $\begin{array}{l}\text { Na escola em que atua estão disponíveis para a inclusão de alunos público-alvo } \\
\text { da educação especial: Apoio de profissionais especializados ? Ex. }\end{array}$ \\
\hline Professor 1 & Sim. Professora em atendimento individualizado. \\
\hline Professor 2 & Sim. Prof. Intérprete e equipe de Educação Especial. \\
\hline Professor 3 & Sim. Em períodos opostos ao escolar. \\
\hline Professor 4 & Sim. Professora de Educação Especial. \\
\hline Professor 5 & Sim. \\
\hline Professor 6 & $\begin{array}{l}\text { Sim. Somente a citada anteriormente e uma equipe que tria as crianças indicadas (não } \\
\text { temos contato, só lemos o contra relatório). }\end{array}$ \\
\hline Professor 7 & Sim. Professor do AEE atende em período oposto na sala de recursos. \\
\hline Professor 8 & Sim. Intérprete de libras e professora de AEE. \\
\hline Professor 9 & Sim. Professora Ed. Especial. \\
\hline Professor 10 & Sim. Professora de atendimento educacional especializado. \\
\hline Professor 11 & Não. \\
\hline Professor 12 & Sim. \\
\hline Professor 13 & Sim. A professora de educação especial e a coordenadora. \\
\hline
\end{tabular}


Fonte: Elaboração dos autores.

Sobre o apoio de profissionais especializados, apenas um professor respondeu que a escola não disponibiliza, o que é bastante curioso, uma vez que todos os respondentes eram da mesma escola. Embora tenha indicado que possui aluno com deficiência, esse professor, o P11, não identificou o tipo de deficiência. Talvez esse aluno não tenha atendimento educacional especializado, e por isso esse professor não identifica esse profissional na escola, o que é no mínimo uma incoerência. Os outros professores referem a professora de atendimento educacional especializado, o intérprete de Libras, e um deles menciona equipe de Educação Especial, possivelmente fazendo menção a uma equipe da Secretaria Municipal de Educação do referido município, composta por pedagogo, psicólogo, fonoaudiólogo e assistente social, que é responsável pela triagem e avaliação dos alunos indicados para o atendimento educacional especializado em sala de recursos. É importante pontuar o papel dos profissionais mencionados no processo de inclusão escolar, no entanto, percebemos que a escola carece do apoio de outros parceiros atuando em colaboração nesse processo.

Gráfico 7. Dados da questão

6.

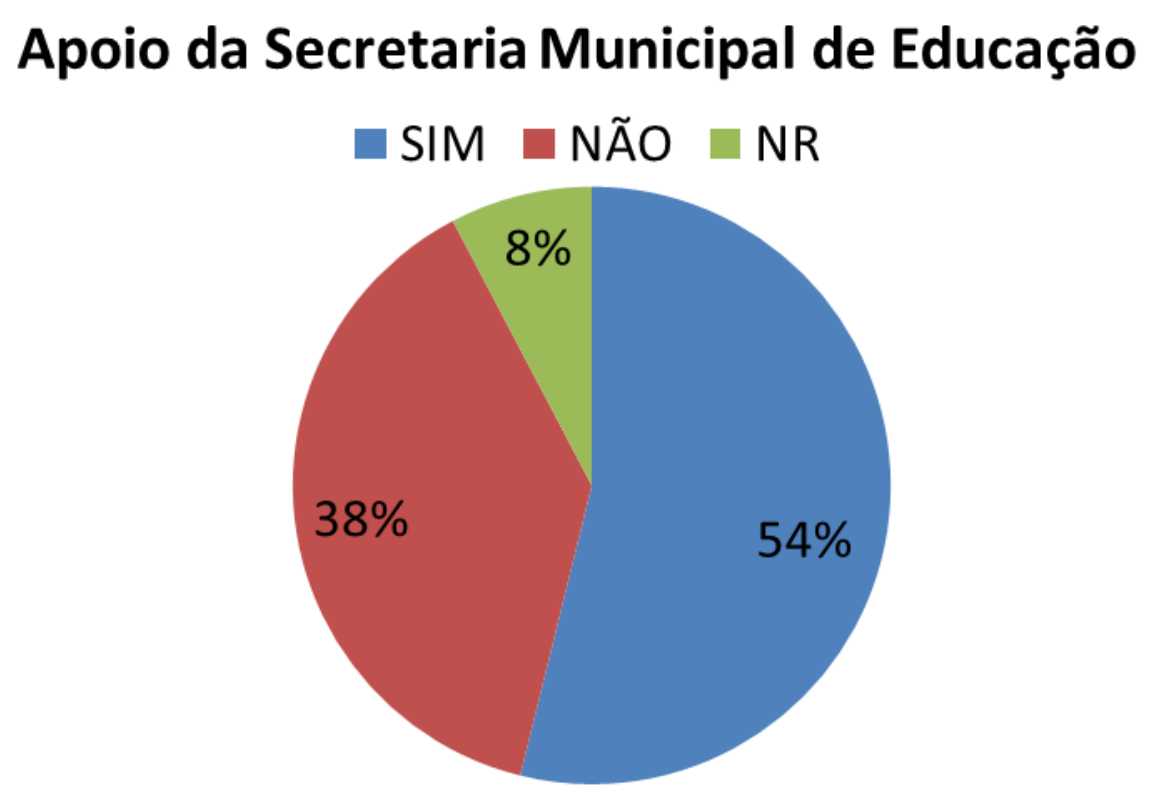

Fonte: Elaboração dos autores. 
Quadro 10. Questão 6 do questionário aplicado aos professores.

\begin{tabular}{|l|l|}
\hline Questão 6 & $\begin{array}{l}\text { Na escola em que atua estão disponíveis para a inclusão de alunos público alvo da } \\
\text { educação especial: Apoio da Secretaria Municipal de Educação ? Ex. }\end{array}$ \\
\hline Professor 1 & Não sei. \\
\hline Professor 2 & Sim. Oferece apoio (orientação) e cursos. \\
\hline Professor 3 & Não. Não temos apoio, somos sozinhas. \\
\hline Professor 4 & Não. \\
\hline Professor 5 & Não. \\
\hline Professor 6 & $\begin{array}{l}\text { Sim. Da equipe que tria (psicólogo e psicopedagogo) e faz a anamnese do } \\
\text { encaminhamento. }\end{array}$ \\
\hline Professor 7 & Sim. Equipe multidisciplinar. \\
\hline Professor 8 & Sim. Cursos. \\
\hline Professor 9 & Não. \\
\hline Professor 10 & Sim. Equipe de Educação Especial (para diagnóstico). \\
\hline Professor 11 & Não. \\
\hline Professor 12 & Sim. \\
\hline Professor 13 & Sim. Nos oferece um prof. De educação especial de plantão. \\
\hline
\end{tabular}

Fonte: Elaboração dos autores.

Finalizando os elementos disponíveis para favorecer a inclusão, foi perguntado sobre o apoio da Secretaria Municipal de Educação. As respostas são ambíguas, com $54 \%$ dizendo que têm esse apoio, $38 \%$ dizendo que não e um professor dizendo que não sabe. Mais uma vez nos compete refletir sobre esse dado, considerando as diferentes percepções de um mesmo elemento advindas de professores de uma mesma escola. Além do trabalho da Educação Especial, já mencionado anteriormente, dois professores apontaram cursos e orientação como parte desse apoio. O que nos chama a atenção é a não existência de um trabalho sistemático por parte da Secretaria de Educação que objetive uma formação em serviço capaz de subsidiar o trabalho pedagógico do professor e da escola de maneira a torná-la acessível para todos os alunos. 
Gráfico 8. Dados da questão 7.

\section{Como você classifica o grau de dificuldade para o desenvolvimento de práticas pedagógicas em classes regulares com alunos público alvo da educação especial?}

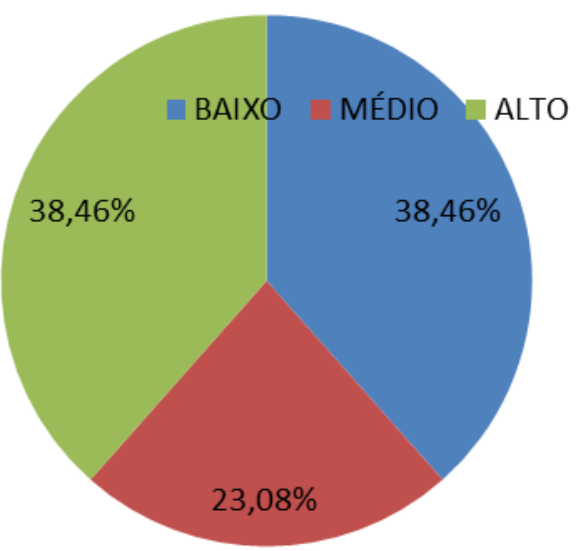

Fonte: Elaboração dos autores.

Quadro 11. Questão 7 do questionário aplicado aos professores.

\begin{tabular}{|l|l|}
\hline Questão 7 & $\begin{array}{l}\text { Como você classifica o grau de dificuldade para o desenvolvimento de práticas } \\
\text { pedagógicas em classes regulares com alunos público alvo da educação especial? ( ) } \\
\text { inexistente ( ) baixo ( ) médio ( ) alto. Por que? }\end{array}$ \\
\hline Professor 1 & Baixo. A atividade é feita, porém de forma adaptada as suas necessidades. \\
\hline Professor 2 & Médio. \\
\hline Professor 3 & Baixo. Não temos apoio somos sozinhas. \\
\hline Professor 4 & Alto. Não temos materiais adaptados. \\
\hline Professor 5 & Alto. \\
\hline Professor 6 & $\begin{array}{l}\text { Alto. Impossível dispensar atenção à 1 aluno com } 26 \text { esperando orientação. Falta de tempo } \\
\text { e indisciplina. }\end{array}$ \\
\hline Professor 7 & $\begin{array}{l}\text { Alto. Falta uma cultura de inclusão que permeia a prática pedagógica de todos os } \\
\text { envolvidos no processo de ensino e aprendizagem desses alunos. }\end{array}$ \\
\hline Professor 8 & Baixo. Depende do aluno. \\
\hline Professor 9 & Baixo. Não tenho formação específica para tal. \\
\hline Professor 10 & Médio. \\
\hline Professor 11 & $\begin{array}{l}\text { Alto. Se não temos formação específica, nem material adequado, é difícil desenvolver } \\
\text { atividades satisfatórias. }\end{array}$ \\
\hline
\end{tabular}




\begin{tabular}{|l|l|}
\hline Professor 12 & Médio. \\
\hline Professor 13 & Baixo. Não somos especializadas. \\
\hline
\end{tabular}

Fonte: Elaboração dos autores.

A questão sete pedia aos professores que classificassem o grau de dificuldade para realização de um trabalho inclusivo. Obtivemos o mesmo número de respostas Baixo e Alto, porém as explicações demonstram que alguns professores não entenderam a questão, uma vez que assinalaram baixo, mas justificaram afirmando não terem formação, especialização e, denunciando mais uma vez o trabalho isolado. Sendo assim, é possível verificar que a grande maioria dos professores referem não ser capazes de desenvolver práticas pedagógicas que beneficiem todos os seus alunos.

Quadro 12. Questão 8 do questionário aplicado aos professores.

\begin{tabular}{|l|l|}
\hline Questão 8 & $\begin{array}{l}\text { Qual tipo de formação você possui para trabalhar com alunos da Educação } \\
\text { Especial em classes regulares? }\end{array}$ \\
\hline Professor 1 & Graduação. \\
\hline Professor 2 & Graduação, especialização e Mestrado em Educação Especial. \\
\hline Professor 3 & Graduação. \\
\hline Professor 4 & Graduação. \\
\hline Professor 5 & Graduação e especialização. \\
\hline Professor 6 & Graduação. \\
\hline Professor 7 & Graduação e habilitação em Educação Especial. \\
\hline Professor 8 & Especialização. \\
\hline Professor 9 & Graduação. \\
\hline Professor 10 & Curso. \\
\hline Professor 11 & Graduação. \\
\hline Professor 12 & Especialização. \\
\hline Professor 13 & Graduação. \\
\hline
\end{tabular}

Fonte: Elaboração dos autores.

Sobre a formação para a atuação com alunos da Educação Especial em classes comuns, 7 dos 13 professores mencionaram apenas a graduação, 4 mencionaram especialização, 1 habilitação em Educação Especial, 1 curso e 1 Mestrado em Educação Especial. Ao analisarmos as respostas dos professores com habilitação e com Mestrado, verificamos que o nível mais elevado de estudo na área não representa uma posição mais inclusiva, e no caso desses professores na verdade a posição é bastante contrária. A 
cultura inclusiva, mencionada anteriormente por um professor, parece não depender, pelo menos não totalmente, do conhecimento teórico sendo preciso que haja um movimento de formação em serviço capaz de ser uma proposta abrangente de formação que desenvolva não somente aspectos teóricos como em um curso, mas estudos de casos reais dos professores participantes, criação de espaço de reflexão por parte dos mesmos de seu trabalho enquanto profissionais, de suas práticas pedagógicas, de suas concepções sobre o papel da escola e de todos os elementos envolvidos nessa atuação. Conforme Carneiro, Dall'Acqua e Caramori (2014):

Políticas de formação em serviço de professores que sejam capazes de acompanhar as mudanças necessárias à consolidação de um modelo de escola para todos, fazem parte de um rol de ações necessárias à superação das contradições existentes em nosso sistema educacional pois, o professor atua diretamente $\mathrm{e}$ diariamente com a formação das novas gerações que, a rigor, podem concretizar as mudanças (CARNEIRO, DALL'ACQUA e CARAMORI, 2014, p. 23).

Gráfico 9. Dados da questão

9.

\section{Como você avalia sua formação para lecionar em classes com alunos de inclusão?

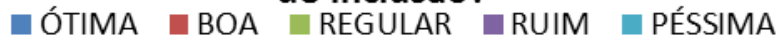

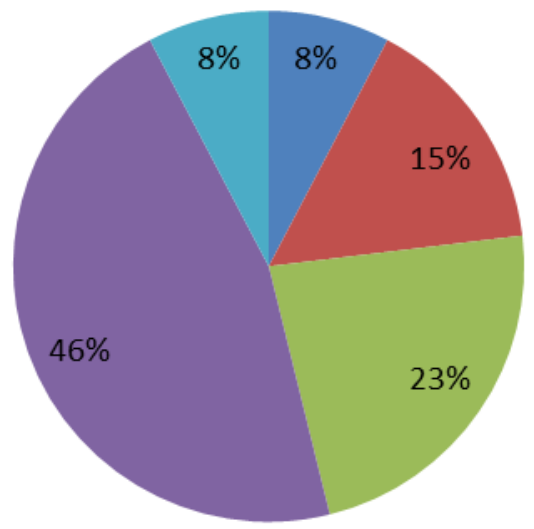

Fonte: Elaboração dos autores.

Quadro 13. Questão 9 do questionário aplicado aos professores.

\begin{tabular}{|l|c|}
\hline Questão 9 & $\begin{array}{c}\text { Como você avalia sua formação para } \\
\text { lecionar em classes com alunos de inclusão? }\end{array}$ \\
\hline Professor 1 & Ruim. \\
\hline
\end{tabular}




\begin{tabular}{|l|c|}
\hline Professor 2 & Ótima. \\
\hline Professor 3 & Ruim. \\
\hline Professor 4 & Ruim. \\
\hline Professor 5 & Boa. \\
\hline Professor 6 & Ruim. \\
\hline Professor 7 & Regular. \\
\hline Professor 8 & Regular. \\
\hline Professor 9 & Ruim. \\
\hline Professor 10 & Regular. \\
\hline Professor 11 & Péssima. \\
\hline Professor 12 & Boa. \\
\hline Professor 13 & Ruim. \\
\hline
\end{tabular}

Fonte: Elaboração dos autores.

Perguntados sobre como avaliavam sua formação para o trabalho inclusivo, $77 \%$ dos professores responderam que achavam péssima, ruim ou regular, o que reforça a tese anteriormente apresentada sobre a necessidade urgente de formação em serviço com tal objetivo.

Quadro 14. Questão 10 do questionário aplicado aos professores.

\begin{tabular}{|l|l|}
\hline Questão 10 & $\begin{array}{l}\text { Que açães você considera necessárias para que a inclusão de alunos público alvo } \\
\text { da educação especial ocorra de maneira satisfatória? }\end{array}$ \\
\hline Professor 1 & Materiais específicos, professores atuando junto aos professores de classe. \\
\hline Professor 2 & $\begin{array}{l}\text { Os professores das salas de aula regulares devem receber mais formação. Ainda há } \\
\text { muito preconceito e recusa em relação à inclusão. }\end{array}$ \\
\hline Professor 3 & Uma auxiliar para cada aluno especial. \\
\hline Professor 4 & Ambiente adaptado e material adequado às necessidades dos alunos. \\
\hline Professor 5 & Em branco. \\
\hline Professor 6 & $\begin{array}{l}\text { Apoio de equipe multidisciplinar que atuem em conjunto com o professor regente e } \\
\text { não apenas o orientem verbalmente. Além disso uma frequência maior pois esse } \\
\text { "apoio" ou orientação ocorre uma vez após a anamnese quando lemos o contra- } \\
\text { relatório. }\end{array}$ \\
\hline Professor 7 & $\begin{array}{l}\text { Uma cultura de inclusão, formação na qual se contemple a realidade na qual esse aluno } \\
\text { é inserido; bem como o papel do professor nesse processo; recursos e estrutura tais } \\
\text { como: classes reduzidas, material didático de apoio, plano de adaptação curricular em } \\
\text { consonância com o plano docente da classe regular; enfim, condições de promover a } \\
\text { efetiva inclusão que foi idealizada. }\end{array}$ \\
\hline Professor 8 & O professor deve se envolver e participar de formações. \\
\hline Professor 9 & \begin{tabular}{l} 
Em branco. \\
\hline Professor 10
\end{tabular} \\
\hline
\end{tabular}




\begin{tabular}{|l|l|}
\hline Professor 11 & $\begin{array}{l}\text { Que haja acompanhamento de um profissional com formação adequada para } \\
\text { proporcionar atendimento a, no máximo, 3 ou 5 alunos por vez. }\end{array}$ \\
\hline Professor 12 & Participação da comunidade e/ou família; formação continuada. \\
\hline Professor 13 & Especialização do professor para cada caso que surge na sala de aula. \\
\hline
\end{tabular}

Fonte: Elaboração dos autores.

Encerrando o questionário foi perguntado sobre que ações ele achava necessárias para que a inclusão de alunos público-alvo da Educação Especial acontecesse de forma satisfatória. Os professores elencaram recursos estruturais, materiais e humanos, mas fundamentalmente, formação e colaboração. Embora as vezes a colaboração seja entendida de forma equivocada, como a do professor P3 que sugere 1 auxiliar para cada aluno especial, uma formação condizente com o princípio de escola para todos poderia apresentar os caminhos possíveis de um trabalho pedagógico eficaz.

\section{Conclusões}

Iniciamos este estudo a partir de algumas indagações sobre como o processo de inclusão escolar de alunos público-alvo da Educação Especial vem ocorrendo em nosso país. Embora tenhamos realizado um estudo de caso que analisou uma única unidade escolar; (portanto os dados levantados não possam ser generalizados), são dados que oferecem elementos para uma reflexão necessária sobre esta temática. Observamos que o oferecimento de matrícula, primeiro passo no caminho da escola para todos, portanto fundamental, não garante ensino e aprendizagem. A concepção dos professores, segmento envolvido diretamente no processo, não condiz com os princípios inclusivos, uma vez que não se percebem como agentes da mudança, o que aponta para a necessidade de políticas de formação que institucionalize, definindo tempo e espaço, uma formação em serviço que considere a realidade da escola, do professor e dos alunos ali matriculados. A prática pedagógica inclusiva, aquela que responde às necessidades variadas dos alunos, precisa ser construída- não sabemos trabalhar com todos os alunos porque historicamente a escola selecionou e homogeneizou o grupo de educandos e seus modelos pedagógicos. Finalizando, é preciso criar uma cultura de colaboração, envolvendo professores comuns, professores especializados, gestão da escola, família, parceiros da comunidade, enfim, todos os recursos humanos capazes de oferecer à escola e aos alunos condições plenas de desenvolvimento. 
A inclusão escolar faz parte de um movimento que pressupõe mudança de modelo, de estrutura e de política, se constrói a partir de dentro, com análise crítica do que está posto e reflexão propositiva para onde vamos.

\section{Referências}

BRASIL. Constituição (1988). Constituição da República Federativa do Brasil. 10. ed. Brasília, DF: Senado, 1998.

Instituto Nacional de Estudos e Pesquisas Educacionais Anísio Teixeira. Resumo técnico - censo escolar 2014. Brasília, DF: 2014. Disponível em: <http://download.inep.gov.br/download/censo/2010/divulgacao_censo_2010_201210.p df>. Acesso em: 11 mar. 2016.

CARNEIRO, R. U. C., DALL'ACQUA, M. J. C. e CARAMORI, P. M. (orgs.). Educação Especial e Inclusiva? Mudanças para a escola e a sociedade. Jundiaí, Paco Editorial: 2014.

FRIEND, M. Na interview with... Intervention in school and clinic. Vol. 37, no. 4, p. 223-228, March 2002.

LUDKE, Menga; ANDRÉ, Marli E. D. A. Pesquisa em educação: abordagens qualitativas. São Paulo: EPU, 1986.

ONU. Declaração Universal dos Direitos Humanos. 1948. Disponível em. <http://www.onu-brasil.org.br/documentos_direitoshu manos.php> . Acesso em 19 de ago. de 2015.

PALMA, D. T. Escolas do campo e Atendimento Educacional Especializado em Sala de Recursos Multifuncional. 2016. 140f. Dissertação (Mestrado em Educação Escolar). Universidade Estadual Paullista "Júlio de Mesquista Filho", Faculdade de Ciências e Letras. Araraquara, 2016.

PASCHOALICK, W.C. Análise do Processo de Encaminhamento de Crianças às Classes Especiais para Deficientes Mentais desenvolvidos nas escolas de $\mathbf{1}^{\circ}$ grau da Delegacia de Ensino de Marília. Dissertação (Mestrado em Educação). Pontifícia Universidade Católica. São Paulo, 1981.

RIPLEY, S. Collaboration between general and special education teachers. ERIC Digest, \#ED409317, 1997.

YIN, R.K. Estudo de Caso: Planejamento em Métodos. 5. ed. Porto Alegre : Bookman, 2010. 


\section{Como referenciar este artigo}

CARNEIRO, Relma Urel Carbone.; UEHARA, Flávia. A inclusão de alunos público alvo da educação especial no ensino fundamental I através do olhar dos professores. Revista Ibero-Americana de Estudos em Educação, v. 11, n. esp. 2, p.911-934, 2016. Disponível em: <https://dx.doi.org/10.21723/riaee.v11.esp2.p911-934>. E-ISSN: 19825587.

\section{Sobre os autores}

${ }^{i}$ UNESP - Universidade Estadual Paulista. Faculdade de Ciências e Letras - Pós-graduação em Educação Escolar. Araraquara - SP - Brasil. 14800-901 - relmaurel@ fclar.unesp.br

ii Aluna especial. UNESP - Universidade Estadual Paulista. Faculdade de Ciências e Letras - Pósgraduação em Educação Escolar. Araraquara - SP - Brasil. 14800-901 - ueharafm@ yahoo.com 